\title{
Phacoemulsification And Zonular Weakness: Contribution Of The Capsular Tension Ring With A Thread
}

This article was published in the following Dove Press journal: Clinical Ophthalmology

\author{
Nasreddine Oudjani $\mathbb{D I}^{\prime}$ \\ Didier Renault ${ }^{2,3}$ \\ Emilie Courrier ${ }^{2}$ \\ Yacine Malek'
}

'Outpatient Ophthalmology Clinic, Cité les allées du 20 août 1955, Skikda 21000, Algeria; ${ }^{2}$ Corneal Graft Biology, Engineering and Imaging Laboratory, EA252 I, Federative Institute of Research in Sciences and Health Engineering, Faculty of Medicine, Jean Monnet University, Saint-Etienne, France; ${ }^{3}$ Laboratoires Théa, Clermont-Ferrand Cedex 2 63017, France
Correspondence: Nasreddine Oudjani Outpatient Ophthalmology Clinic Cité les allées du 20 août 1955, Skikda 21000 Algeria

Tel +213661210000

Fax +21338722077

Email dr_oudjani_ophtalmo@yahoo.fr
Purpose: Cataract surgery in patients suffering from zonular weakness can be difficult and lead to severe complications. The insertion of capsular tension rings to stabilize the capsular bag along all steps of the phacoemulsification is an option, although can be difficult to remove intra- or post-operatively. A capsular tension ring with a thread is a safe alternative, which allows its easy removal at the end of the surgery.

Patients and methods: Retrospective study of regular practice on 14 patients with zonular weakness who underwent phacoemulsification. Among them, 12 suffered from pseudoexfoliative syndrome and 2 suffered from a post-traumatic cataract. All benefited from the use of a capsular tension ring with a thread during their surgery.

Results: All surgeries were successful. Capsular tension ring with a thread was all removed at the end of surgery without any complication.

Conclusion: The addition of a thread to the capsular tension ring is a simple modification that enhances its use by facilitating its intraoperative removal if necessary or at the end of surgery.

Keywords: weak zonule, capsular bag, cataract, posterior dislocation, trick

\section{Introduction}

The author estimates that between 150,000 and 200,000 cataract surgeries a year are performed in Algeria. According to the DREES in France, this is the most common surgery performed, with nearly 830,000 completed in $2016 .{ }^{1}$ One of the main, serious intraoperative complications of cataract surgery is the posterior dislocation of the lens or its nucleus, caused by capsular rupture or zonular disinsertion. This complication is common in patients who have experienced previous zonular fragility and is present in numerous etiologies, ${ }^{2,3}$ in order of frequency: the zonular degeneration of pseudo-exfoliative syndromes (estimated at $25-30 \%$ of the causes in Algeria), ${ }^{4-7}$ eye injuries, ${ }^{7,8}$ strong myopia, ${ }^{7}$ history of vitreoretinal surgery, fibroelastic tissue pathologies in Marfan's disease ${ }^{7,9}$ or homocystinuria. ${ }^{10}$

The capsular or zonular tension ring (CTR) was designed in the early $1990 \mathrm{~s}^{11}$ to stabilize the capsular bag and consolidate weak zonules during all stages of surgery, including phacoemulsification. ${ }^{3,7,12-15}$ It distributes the tension forces acting on the still functional zonular fibers and thus reduces the risk of capsular failure and posterior dislocation of the lens. ${ }^{11,15}$ However, its withdrawal is difficult and can be traumatic. It is therefore generally left in place at the end of surgery or even fixed to the sclera. ${ }^{14}$ Nevertheless, it is preferable to leave a minimum of foreign 
bodies in the surgical site, and consequently, CTR is a relatively unused tool even in cases of phacodonesis.

The aim of this study is to describe how the employment of a thread facilitates the use of the tension ring and allows its removal at the end of phacoemulsification on a weak zonule.

\section{Materials And Methods}

\section{Surgical Technique}

The surgical technique consisted in the use of a thread (Vicryl violet 7/0, Ethicon, NJ, USA) attached to the eye of the CTR (Medicontur, Limas, France), at the end of the medical device, by a knot and a counter-node
(Figure 1A and B). The tension ring was placed inside the anterior chamber, in the capsular bag, under the anterior capsulorhexis by a counterclockwise movement, allowing the zonule to be tensioned (Figure 1C and D). The thread then came out outside the eye through the incision. The zonule was thus stabilized during all phacoemulsification steps. At the end of the surgery, after the placement of a large diameter implant and cohesive viscoelastic (Provisc, Alcon Laboratories, TX, USA), the ring was removed using the thread sticking out from the incision by a clockwise movement (Figure $1 \mathrm{E}$ and F). A video support is available online at http:// youtu.be/9vazuWf0Djg.

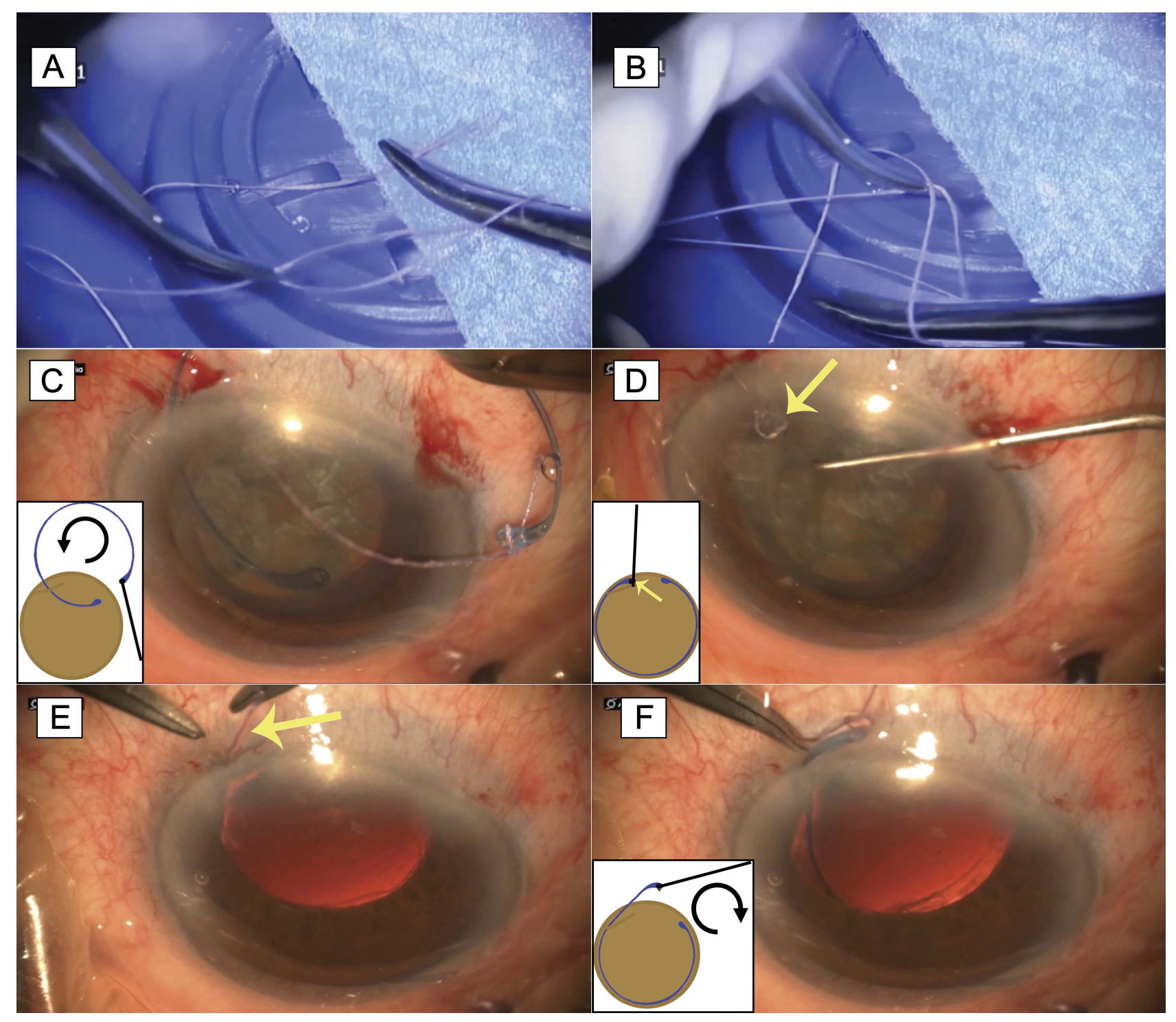

Figure I (A) Passing of the thread at one end of the capsular tension ring and hanging of the suture with a knot. (B) Counter knot. (C) Placing the ring in the capsular bag under the anterior capsulorhexis, by a counterclockwise movement. (D) Capsular ring in place. The knot is placed inside, under the iris (yellow arrow) and the thread emerges through the incision. (E and $\mathbf{F}$ ) Removal of the tension ring by pulling of the thread protruding from the incision (yellow arrow) clockwise. 


\section{Patients}

This real-life retrospective study involved 14 eyes of 14 patients $(9$ men and 5 women aged between 33 and 80 years) operated on by phacoemulsification by the same surgeon (Dr N. Oudjani) between 12th October 2015 and 2nd November 2017 at the outpatient ophthalmology clinic in Skikda (Algeria). All the patients signed an inform consent form before the cataract surgery. Patient consent to review their medical records was not required by an institutional review board and local law in Algeria for this type of real-life retrospective analysis including a surgery using common devices as the CTR and surgical thread. However, patient data confidentiality and compliance were respected. All had zonular weakness discovered intraoperatively: 12 suffered from pseudo-exfoliation of the capsular and 2 from post-traumatic lesions. All patients were reviewed post-operatively at D1, D3, D15, D30 and every 3 months thereafter.

\section{Results}

The phacoemulsifications were carried out without incident and the tension rings with a thread were removed each time without complication at the end of the surgery. No dislocation or subluxation was noted during post-operative follow-up (mean 14.5 months, from 3 to 28 months).

\section{Discussion}

Cataract surgery on weak zonules can be risky. ${ }^{16}$ A solution to zonules weakness is the use of CTR during surgery. However, this practice remains limited due to difficulties relating to its removal, post-operative complications such as dislocation in the vitreous of the capsular bag, implant and ring assembly, ${ }^{2}$ and the existence of alternative techniques (implantation in the sulcus, ${ }^{17}$ implant clipped to the iris ${ }^{18}$ ). Our technique involving a knotted thread at one end of the ring not only stabilizes the fragile capsular bag, but also allows its removal quickly and safely in the event of complications during installation and permits its safe removal at the end of the surgery. The placement and the removal of the thread are fast (around less than $1 \mathrm{~min}$ ), without complications on the analyzed series. The post-operative procedure is comparable to a normal one. The thread, out of the eyeball, is sufficiently loose for not exerting any risky traction of the anterior capsule during the surgery and when it is removed even in case of risky situations as very deep anterior chamber (high myopia) or swinging anterior chamber depth or small anterior capsulorhexis.

\section{Conclusion}

The CTR is an excellent option for consolidating weak zonules during phacoemulsification procedures. Our suture security technique using a CTR with a thread eliminates the risk of it falling into the vitreous during the procedure and facilitates its removal at the end of the surgery.

\section{Acknowledgments}

We would particularly like to thank Victor Lambert, an ophthalmology intern at the University Hospital of SaintEtienne, for his contribution to the review of this article and his wise advice, as well as Bouchta Karrich of Laboratoires Théa for his bibliographical research.

\section{Disclosure}

The authors have declared that no competing interest exists. This study does not include financial support. The authors have no proprietary or commercial interest in any materials discussed in this article and have no conflicts of interest in this work.

\section{References}

1. De Peretti C, Oberlin P, Villain M, Daien V Le traitement de la cataracte primaire est la plus fréquente des interventions chirurgicales. DREES, Etudes et Résultats. 2018. Available from: https://drees.solidarites-sante. gouv.fr/IMG/pdf/er 1056.pdf. Accessed March 28, 2019.

2. Li B, Wang Y, Malvankar-Mehta MS, Hutnik CM. Surgical indications, outcomes, and complications with the use of a modified capsular tension ring during cataract surgery. J Cataract Refract Surg. 2016;42(11):1642-1648. doi:10.1016/j.jcrs.2016.10.007

3. Weber $\mathrm{CH}$, Cionni RJ. All about capsular tension rings. Curr Opin Ophthalmol. 2015;26(1):10-15. doi:10.1097/ICU.0000000000000118

4. Skuta GL, Parrish RK 2nd, Hodapp E, Forster RK, Rockwood EJ Zonular dialysis during extracapsular cataract extraction in pseudoexfoliation syndrome. Arch Ophthalmol. 1987;105(5):632-634. doi:10.1001/archopht.1987.01060050050035

5. Schlotzer-Schrehardt U, Naumann GO. A histopathologic study of zonular instability in pseudoexfoliation syndrome. Am J Ophthalmol. 1994;118(6):730-743. doi:10.1016/S0002-9394(14)72552-8

6. Sein J, Galor A, Sheth A, Kruh J, Pasquale LR, Karp CL. Exfoliation syndrome: new genetic and pathophysiologic insights. Curr Opin Ophthalmol. 2013;24(2):167-174. doi:10.1097/ICU.0b013e32835d5d11

7. Jiraskova N, Rozsival P, Urminsky J. [Results of 32 cataract operations using the capsular ring]. Cesk Slov Oftalmol. 2001;57(3):165-168.

8. Marin MI, Tejero TR, Dominguez FM, Gutierrez ME. Ocular injuries in midfacial fractures. Orbit. 1998;17(1):41-46. doi:10.1076/orbi.17. 1.41.7950

9. Mir S, Wheatley HM, Hussels IE, Whittum-Hudson JA, Traboulsi EI. A comparative histologic study of the fibrillin microfibrillar system in the lens capsule of normal subjects and subjects with Marfan syndrome. Invest Ophthalmol Vis Sci. 1998;39(1):84-93.

10. Harrison DA, Mullaney PB, Mesfer SA, Awad AH, Dhindsa H. Management of ophthalmic complications of homocystinuria. Ophthalmology. 1998;105(10):1886-1890. doi:10.1016/S0161-6420(98) 91035-1 
11. Menapace R, Findl O, Georgopoulos M, Rainer G, Vass C, Schmetterer $\mathrm{K}$. The capsular tension ring: designs, applications, and techniques. $J$ Cataract Refract Surg. 2000;26(6):898-912. doi:10.1016/S0886-3350 (00)00446-6

12. Gimbel HV, Sun R, Heston JP. Management of zonular dialysis in phacoemulsification and IOL implantation using the capsular tension ring. Ophthalmic Surg Lasers. 1997;28(4):273-281.

13. Moreno-Montanes J, Sainz C, Maldonado MJ. Intraoperative and postoperative complications of Cionni endocapsular ring implantation. J Cataract Refract Surg. 2003;29(3):492-497. doi:10.1016/ S0886-3350(02)01604-8

14. Cionni RJ, Osher RH. Management of profound zonular dialysis or weakness with a new endocapsular ring designed for scleral fixation. J Cataract Refract Surg. 1998;24(10):1299-1306. doi:10.1016/ S0886-3350(98)80218-6
15. Rai G, Sahai A, Kumar PR. Outcome of Capsular Tension Ring (CTR) implant in complicated cataracts. J Clin Diagn Res. 2015;9 (12):NC05-NC07. doi:10.7860/JCDR/2015/10425.6999

16. Lu LW, Fine IH. Phacoemulsification in Difficult and Challenging Cases. Thieme; 1999.

17. Mohebbi M, Bashiri SA, Mohammadi SF, et al. Outcome of singlepiece intraocular lens sulcus implantation following posterior capsular rupture during phacoemulsification. J Ophthalmic Vis Res. 2017;12(3):275-280. doi:10.4103/jovr.jovr_181_15

18. Raciti MW, Majmudar PA. Phakic IOLs: sulcus versus iris-claw versus angle-supported: complications and outcomes. Curr Ophthalmol Rep. 2013;1(1):45-49. doi:10.1007/s40135-012-0001-1
Clinical Ophthalmology

\section{Publish your work in this journal}

Clinical Ophthalmology is an international, peer-reviewed journal covering all subspecialties within ophthalmology. Key topics include: Optometry; Visual science; Pharmacology and drug therapy in eye diseases; Basic Sciences; Primary and Secondary eye care; Patient Safety and Quality of Care Improvements. This journal is indexed on PubMed

\section{Dovepress}

Central and CAS, and is the official journal of The Society of Clinical Ophthalmology (SCO). The manuscript management system is completely online and includes a very quick and fair peer-review system, which is all easy to use. Visit http://www.dovepress.com/ testimonials.php to read real quotes from published authors. 